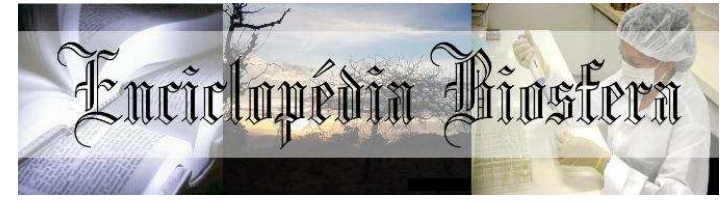

\title{
ANATOMIA MACROSCÓPICA COMPARATIVA DO TELENCÉFALO DE QUATI (Nasua nasua)
}

\author{
Tarley Santos Oliveira ${ }^{1}$, Zenon Silva ${ }^{2}$, Roseâmely Angélica de Carvalho Barros ${ }^{3}$, \\ Bruno Aires Simões ${ }^{4}$, Eduardo Paul Chacur ${ }^{5}$
}

Graduando do Curso de Enfermagem, Universidade Federal de Goiás -

Regional Catalão, Catalão-GO, Brasil. tarley13@live.com

Docente do Instituto de Biotecnologia, Núcleo de Ciências Biológicas,

Universidade Federal de Goiás - Regional Catalão, GO.

Docente do Instituto de Biotecnologia, Núcleo de Ciências Biológicas,

Universidade Federal de Goiás - Regional Catalão, Catalão - GO.

Graduando do Curso de Psicologia, Universidade Federal de Goiás - Regional

Catalão, Catalão-GO, Brasil.

Docente do Instituto de Biotecnologia, Núcleo de Ciências Biológicas,

Universidade Federal de Goiás - Regional Catalão, Catalão - GO.

Recebido em: 08/04/2017 - Aprovado em: 10/06/2017 - Publicado em: 20/06/2017 DOI: 10.18677/EnciBio 2017A250

\begin{abstract}
A Anatomia Comparativa é essencial para descrições e comparações entre espécies que apresentam formas e estrutura corporal similares, quer em nível macroscópico quanto microscópicos. Essa ciência estuda a organização e disposição das estruturas anatômicas que formam o corpo dos animais, inclusive a do homem. O objetivo desta pesquisa é o estudo da organização anatômica macroscópica do Telencéfalo do Quati (Nasua nasua), um componente da fauna do cerrado brasileiro. Materiais e métodos: Neste estudo são dissecados e analisados dois espécimes adultos, machos, que foram coletados mortos às margens de rodovias do Sudeste goiano. (SISBIO 37072/2). Os dados obtidos são descritos e comparados com aqueles da literatura, já bem estabelecida, em cão doméstico. Resultados: O Telencéfalo de Quati é relativamente bem desenvolvido, em relação ao tamanho do animal. Ele é a parte mais desenvolvida do sistema neural e visto como um todo possui um aspecto globoso, comprimido latero-lateralmente exibindo a forma de um grão-de- bico (Cicer arietinum), cuja parte mais larga é voltada caudalmente e a parte mais estreita, mais comprimida e afilada, rostralmente, sendo composto por duas partes denominadas Hemisférios Cerebrais, separadas pela Fissura Longitudinal. Sua superfície é marcada por vários sulcos e giros, dos quais alguns são mais evidentes e outros um tanto mascarados. Embora alguns sulcos sejam mais profundos, mais largos, e relativamente constantes, não é possível identificar com clareza, as áreas topográficas que se caracterizam como Lobos, pois a maioria dos sulcos e giros se estende por todo ou quase todo o hemisfério.
\end{abstract}

RESUMO

PALAVRAS-CHAVE: Anatomia, Quati, Sistema Neural 


\title{
MACROSCOPIC ANATOMY COMPARATIVE OF THE TELENCEPHALON OF COATI (Nasua nasua)
}

\begin{abstract}
The Comparative Anatomy is essential for descriptions and comparisons between species with similar shapes and body structure, either in macroscopic as microscopic level. This science studies the organization and arrangement of the anatomical structures that form the body of animals, including man. The aim of this research is the study of macroscopic anatomical organization of the telencephalon of Coati (Nasua nasua), a component of the Brazilian Cerrado fauna. In this study two adult specimens, males, were dissected and analyzed, which were collected dead on the highways of the southeast of the state of Goiás. (SISBIO 37072/2). The data were described and compared with those of literature, already well established, of domestic dog. The coati's telencephalon is relatively large compared to its size. It is the most developed part of the neural system and, seen as a whole, has a globular, latero-laterally compressed, exhibiting the form of a chickpea (Cicer arietinum), whose widest part is directed caudally and the narrowest part, more compressed and tapering, rostrally, being composed of two parts called Cerebral Hemispheres, separated by the Longitudinal Fissure. Its surface is marked by various sulci and gyri, some of which are more obvious and others somewhat masked. Although some sulci are deeper, wider, and relatively constant, the topographical areas that are characterized as Lobos, could not be identified clearly, since most of sulci and gyri extends all or nearly all the hemisphere.
\end{abstract}

KEYWORDS: Anatomy, Neural System, Coati

\section{INTRODUÇÃO}

A Anatomia é o estudo da organização estrutural dos organismos, e das relações entre as partes que os formam. Essa ciência, como uma das mais antigas entre as Ciências Biomédicas tem raízes de origem no Antigo Egito, a cerca de 4.000 anos $A C$ e desde então vários enfoques têm norteado o seu estudo, entre eles, a Anatomia Comparativa.

A Anatomia Comparativa é essencial para descrições e comparações entre espécies que apresentam formas e estrutura corporal similares, quer em nível macroscópico quanto microscópicos. Essa ciência estuda a organização das estruturas anatômicas que constituem o corpo dos animais, inclusive a do homem. Dentre os principais objetivos da Anatomia comparativa destaca-se relacionar a forma da estrutura com a função desempenhada em relação ao modo em que vive e o habitat natural de cada espécie.

O Quati é um animal de pequeno ou médio porte, podendo chegar a $30,5 \mathrm{~cm}$ de altura, comprimento entre 43 a $66 \mathrm{~cm}$, sem a cauda e pesar até 11,0 $\mathrm{kg}$. O habitat natural do Quati (Nasua nasua) é constituído por florestas e cerrados, onde apresenta comportamento semi-arborícula, subindo e descendo constantemente em árvores, troncos etc. As fêmeas e os jovens geralmente se juntam em grupos de até 30 animais, já os machos possuem hábitos individuais. Esses animais se alimentam de pequenos vertebrados e invertebrados além de frutos silvestres (GREGORES et al., 2010).

A espécie estudada nesta pesquisa pertence ao filo Chordata, ordem Carnívora, classe Mamalia, família Procionidae. Pode ser encontrado no Bioma 
Cerrado e matas circunvizinhas da América do Sul, Central, e do Norte, onde parece bem adaptado, é pouco estudado e apesar de ser um mamífero, apresenta diferenças anatômicas em relação ao Cão doméstico, e outros animais domésticos, nos quais a literatura a cerca da Anatomia está bem estabelecida

O Cerrado é o segundo maior bioma brasileiro, ocupando uma área de mais de dois milhões de $\mathrm{Km}^{2}$. A formação geográfica inclui campos limpos, e campos de altitude, tendo como ecossistemas o cerrado, cerradão, campos, floresta de galeria e cerrado rupestre. Este ambiente geográfico abriga uma alta diversidade biológica, incluindo espécies próprias da região e espécies endêmicas, em corroboração com a heterogeneidade fisionômica (MARINHO FILHO, 1996; OLIVEIRA \& MARQUIS, 2002). O Cerrado apresenta uma complexidade fitofisionomica e faunística tal que alguns autores o consideram como um complexo de biomas (COUTINHO, 2006).

Existem 194 espécies de mamíferos contribuindo para compor a fauna do Cerrado, sendo cerca de 30 famílias e nove ordens: Chiroptera, Rodentia, Carnivora, Didelphimorphia e Xenartha (MARINHO FILHO; et al, 2002). Assim, esta pesquisa objetiva analisar espécimes pertencentes à ordem carnívora, família procionidae, gênero Nasua e espécie Nasua nasua.

O estudo da Anatomia do Sistema Neural de espécies que compõem a fauna do cerrado é de grande importância, inicialmente porque muitas dessas espécies estão em risco de extinção ou em vias de entrarem nesse risco, segundo porque o Sistema Neural, representa um dos aspectos mais importantes da evolução e terceiro porque são escassos na literatura especializada, estudos dessa natureza, nesses grupos taxonômicos. 0 conhecimento da biologia dos componentes de um bioma é essencial, quando o interesse é a organização e implantação de programas de preservação e proteção, porque o restabelecimento da integridade de uma biodiversidade e I ou Bioma, passa pelo conhecimento da biologia dos seus componentes.

O objetivo desta pesquisa foi dissecar e descrever a Anatomia Macroscópica do Telencéfalo do quati, enumerando e caracterizando os sulcos e giros das faces: dorsolateral, inferior e medial dos hemisférios, confrontando os resultados com a literatura pertinente em outros animais.

\section{MATERIAL E MÉTODOS}

Esta é uma pesquisa descritiva comparativa, onde o Telencéfalo foi dissecado, durante o primeiro semestre de 2016, e as estruturas componentes analisadas e descritas com um nível de detalhes possível para o material disponível. Os resultados são confrontados com as descrições pertinentes em Cão Doméstico, visto ser uma literatura relativamente bem estabelecida.

Os dados estatísticos não são relevantes, uma vez que se tratam de resultados descritivos em um número pequeno de espécimes, até porque, são animais silvestres que não podem ser sacrificados para pesquisa. Os dados foram coletados a partir da dissecação de três espécimes de quati (Nasua nasua) os quais foram coletados mortos, por atropelamento, às margens de rodovias de Goiás e ou Minas Gerais (Autorização SISBIO o 37072/2). No laboratório de Anatomia, for am fixados em solução aquosa de Formol a $10 \%$, via perfusão através da artéria femoral e conservados em igual solução.

A preparação das peças anatômicas foi feita por dissecação macroscópica da calota craniana e região posterior do pescoço até a 
exposição completa da calota craniana e coluna vertebral. Com uma serra para gesso, foram realizados cortes dos ossos da calota craniana no plano sagital mediano e para-mediano a três centímetros da primeira, em cada antímero, assim cortes paramedianos como nos arcos das três primeiras vértebras. A remoção dos ossos foi feita de forma cuidadosa e em pequenas porções, utilizando-se osteótomos, boticão, formão e martelo até a exposição total da telencéfalo e da medula espinhal, envoltos pelas meninges. Para a remoção do material de estudo foi feita a secção da medula espinhal e posteriomente o descolamento da dura-máter da base do crânio e secção dos nervos ópticos e outros pontos de fixação. Uma vez fora da carcaça, o material de estudo foi limpo, removendo-se as meninges com uma pinça de relojoeiro e sob lupa com aumento de 10X. Os sulcos e giros, objeto principal de análise, for a m preservados, descritos e fotografados com uma câmera Sony Cyber Shot de 7.2 megapixels.

A terminologia adotada para a descrição dos resultados foi a International Committee on Veterinary Gross Anatomical Nomeclature (2012). A pesquisa foi desenvolvida com parecer favorável do CEUA/UFU ㄲo067/12 do projeto intitulado "Anatomia Descritiva e Comparativa dos Animais Silvestres".

\section{RESULTADOS}

O Telencéfalo de Quati é relativamente grande, em relação ao tamanho do animal. O Telencéfalo é a parte mais desenvolvida do sistema neural e visto como um todo possui um aspecto globoso, comprimido laterolateralmente exibindo a forma de um grão-de-bico (Cicer arietinum), cuja parte mais larga é voltada caudalmente e a parte mais estreita, mais comprimida e afilada, rostralmente, sendo composto por duas partes denominadas Hemisférios Cerebrais, separadas pela Fissura Longitudinal. A superfície de cada hemisfério é marcada por depressões e elevações, as depressões são denominadas "sulcos" e as elevações "giros". Em cada hemisfério pode-se identificar uma Face Dorsolateral; uma Face Inferior e outra Medial.

Sulcos da Face Dorsolateral - A Face Dorsolateral é a maior das três, e a sua superfície é marcada por vários sulcos e giros, dos quais alguns são mais evidentes e outros um tanto mascarados. Embora alguns sulcos sejam mais profundos, mais largos, e relativamente constantes, não é possível identificar com clareza, as áreas topográficas que se caracterizam como Lobos, pois a maioria dos sulcos e giros se estende por todo ou quase todo 0 hemisfério. Próximo à borda ventral do hemisfério, um sulco longitudinal se estende por toda a extensão do hemisfério, é o Sulco Rinal. Na altura da parte médio-Caudal do hemisfério (extremidade rostral da Área piriforme), o Sulco Rinal divide-se em ramo ventral e ramo dorsal. O ramo ventral denomina-se Sulco Rinal Rostral e o ramo dorsal é o Sulco Silviano. O segmento do Sulco Rinal, rostralmente à ramificação que separa o Trato Olfatório abaixo, do arco cortical acima, denomina-se Sulco Rinal Caudal, cuja extremidade se estende até a extremidade rostral do hemisfério. Já bem próximo à extremidade rostral, divide-se em ramo ventral e ramo dorsal.

$\mathrm{Na}$ altura da parte média do Sulco Rinal Rostral surge um sulco bem marcado, que se dirige crânial e dorsalmente, na direção da fissura longitudinal é - Sulco pré- Silviano, o qual, próximo à extremidade rostro-dorsal se ramifica em um ramo rostral e outro caudal, ambos posicionados paralelamente, à Fissura Longitudinal, na mesma altura e em sentidos opostos (rostro-caudal) constituindo 
um sulco único denominado Sulco Proreus. Contornando a extremidade do Sulco Silviano, há um sulco em forma de $U$ irregular e invertido, denominado Sulco ectosilviano.

O Ramo Rostral do U é menor e menos evidente, já o ramo anterior é longo e claramente evidenciável. Dorsalmente ao Sulco Ectosilviano há um profundo sulco em forma de U invertido, é o Sulco Suprasilviano. O Sulco Supra Silviano pode ser dividido em Sulco Supra Silviano Rostral e Sulco Supra Silviano Caudal. Ao longo de toda a extensão do hemisfério estão dsipostos os sulcos: Rinal, Pré Silviano, Silviano, Ectosilviano e Suprassilviano emitem pequenas ramificações nominadas.

Entre o Sulco Supra Silviano Rostral e o Sulco Ectolateral encontra-se um sulco bem marcado, é o Sulco Cruzado, que corresponde à parte rostral do sulco do cíngulo que avança sobre a face dorsolateral. O Sulco Lateral está presente apenas próximo ao Polo Occipital do hemisfério, ainda assim, Muito Rudimentar.

Giros da Face Dorsolateral - A face dorsolateral do Telencéfalo de quati, apresenta-se cortada por numerosos sulcos, os quais delimitam áreas irregulares denominadas giros ou circunvoluções. Próximo à extremidade rostral do hemisfério ventralmente ao Sulco Pró-Reus há um giro relativamente profundo, é o Giro Pró- Reus. Circundando o Sulco Cruzado, está o Giro Sigmoide e delimitado pela fissura longitudinal e pelo Sulco Suprassilviano, uma grande circunvolução se estende por todo o hemisfério desde o Sulco Cruzado até a extremidade occipital, é o Giro Lateral. Pequenos sulcos ao longo do giro lateral conferem um aspecto rugoso à superfície do Giro Lateral. Delimitado dorsalmente pelo Sulco Supra Silviano e ventral /e pelo Ectosilviano estende-se o profundo Giro Ectosilviano, cuja forma de $U$ invertido pode ser dividido em Giros Ectosilviano Rostral e Caudal, sendo o Rostral mais largo do que o caudal.

Disposto na concavidade do Giro Ectosilviano há um giro irregular que circunda o Sulco Silviano, é o Giro Silviano. O Giro Silviano é bastante irregular, sendo o ramo rostral mais longo e mais delgado do que o ramo caudal. Por vezes a parte média do ramo anterior está ausente ou é muito delgada. Pequenos sulcos dispersos por toda a superfície do hemisfério conferem-lhe um aspecto rugoso, como se fossem muitos pequenos giros. As partes caudais do Giro Silviano e Ectosilviano estão dispostas rostro-ventralmente delimitando uma área composta por dois giros separados pelo Sulco Ectosilviano a qual continua rostralmente com a Area Piriforme e juntas formam uma estrutura muito parecida com o Lobo Temporal de outros animais.

Sulcos e Giros da Face Ventral - A face ventral do hemisfério cerebral de Quati é relativamente irregular, mas não apresenta nenhum sulco ou giro bem marcado como a face dorsolateral. A estrutura telencefálica mais desenvolvida na face ventral é a Área Piriforme, esta é uma extensa área cortical em forma de Pêra, com parte mais estreita voltada caudalmente, em continuação com o Giro Parahipocampal. A parte mais larga da Área Piriforme, orientada rostralmente, está conectada ao Trato Olfatório. A Área Piriforme Continua caudalmente com uma vaga, porém pouco pronunciada área que corresponde ao Giro Parahipocampal.

Sulcos e Giros da Face Medial - A face medial do Telencéfalo de Quati apresenta poucas irregularidades. O sulco mais evidente é o Sulco do Cíngulo, que está disposto longitudinalmente ao longo da face medial até a parte média desta, quando se curva bruscamente para o dorso do hemisfério, avançando sobre a face dorsolateral. O sulco do Corpo Caloso é pouco pronunciado e acompanha a face dorsal do corpo caloso. Rostralmente ao Joelho do Corpo caloso um pequeno sulco transversal está presente, é o sulco 
genual. Os giros visíveis na face medial do hemisfério são: o Giro do Cíngulo, Supraesplenial e a face medial do Giro Lateral. Outras estruturas telencefálicas visíveis na face medial são: o corpo caloso bem delimitado, exibindo joelho tronco e esplênio. O Fórnix e o Septo Pelúcido estão presentes, porém pouco evidentes.

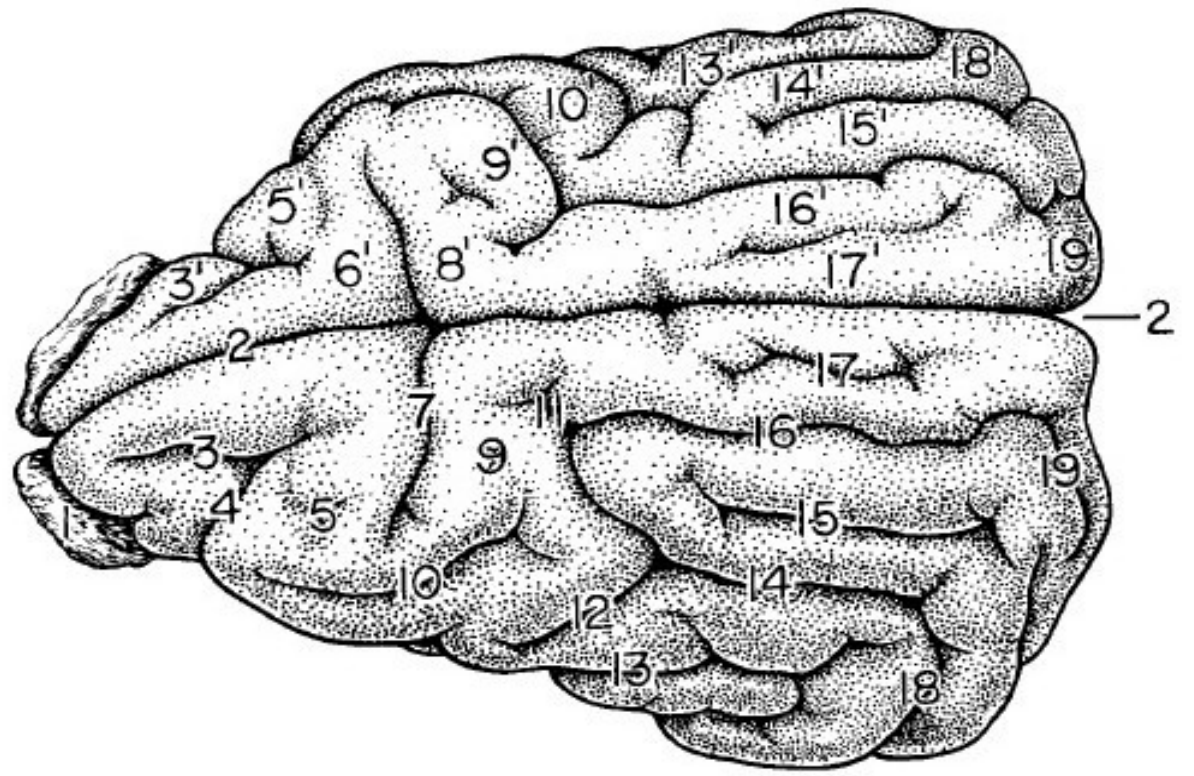

FIGURA 1 - Vista dorsolateral do cérebro de Cão (Miller et al 1964): 1- Bulbo olftório; 2-Fissura longitudinal; 3- Sulco Proreus; 4- Sulco pré silviano 4- Sulco pré cruzado; 6Giro sigmóide cranial; 7- Sulco cruzado; 8- Giro sigmóide caudal; 9- Sulco pós cruzado; 9'Giro pós cruzado; 10- Sulco coronal; 10'- Giro coronal; 11- Sulco pós cruzado, 12- Sulco suprasilviano rostral; 13- Sulco ectosilviano; 13'- Giro ectosilviano; 14- Sulco suprasilviano médio; 14'- Giro suprasilviano médio; 15- Sulco ectolateral; 15'-Giro ectolateral; 16- Sulco lateral; 16'- Giro lateral; 17- Sulco entolateral; 17'- Giro entolateral; 18- Sulco suprasilviano caudal; 18'- Giro suprasilviano caudal; 19- Sulco lateral caudal; 19'- Giro lateral c a u d a I

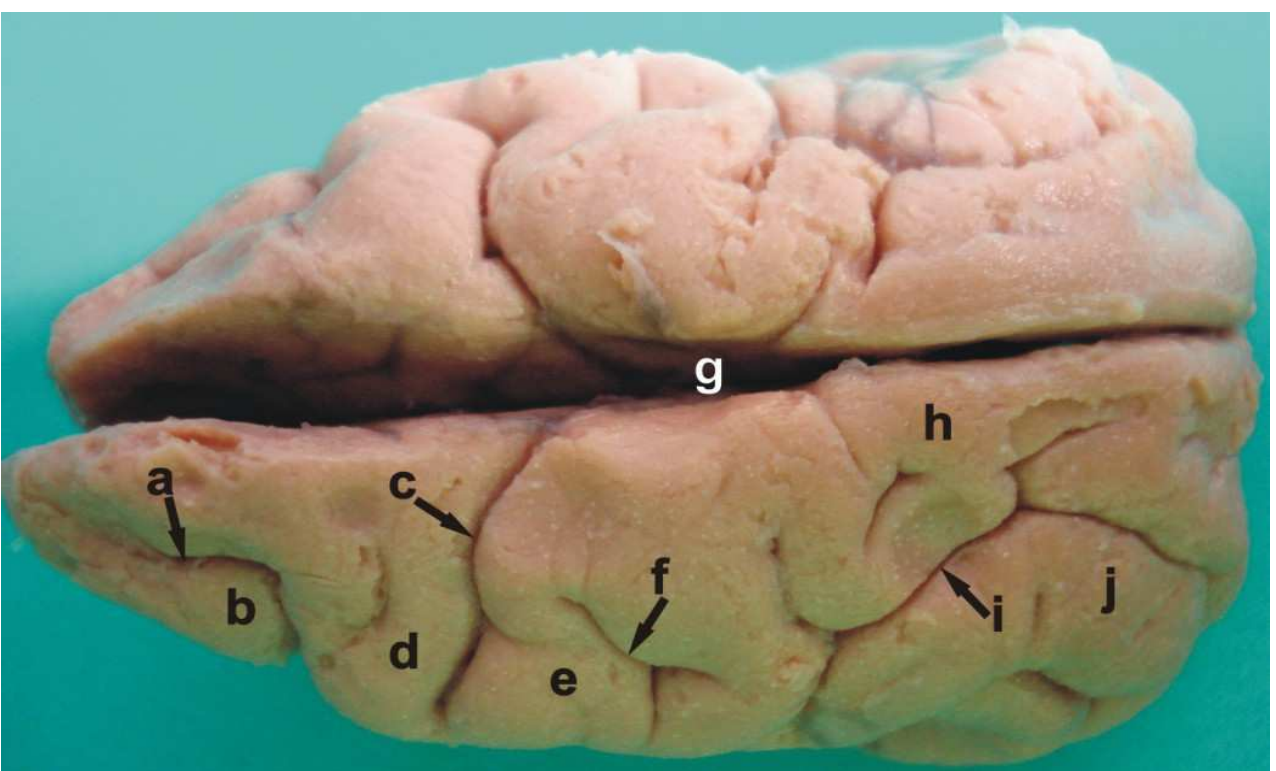

FIGURA 2 - Vista dorsolateral do cérebro de quati: a- Sulco Proreus, b- giro Proreus, cSulco Cruzado, d- Giro Sigmóide Rostral, e- Giro Sigmóide Caudal, f- Giro Pós-cruzado, g- Fissura Longitudinal, h- Giro Lateral (Marginal), i- Sulco Suprasilviano, j- Giro Suprasilviano. Fonte: Tarley Santos Oliveira, Zenon Silva. 


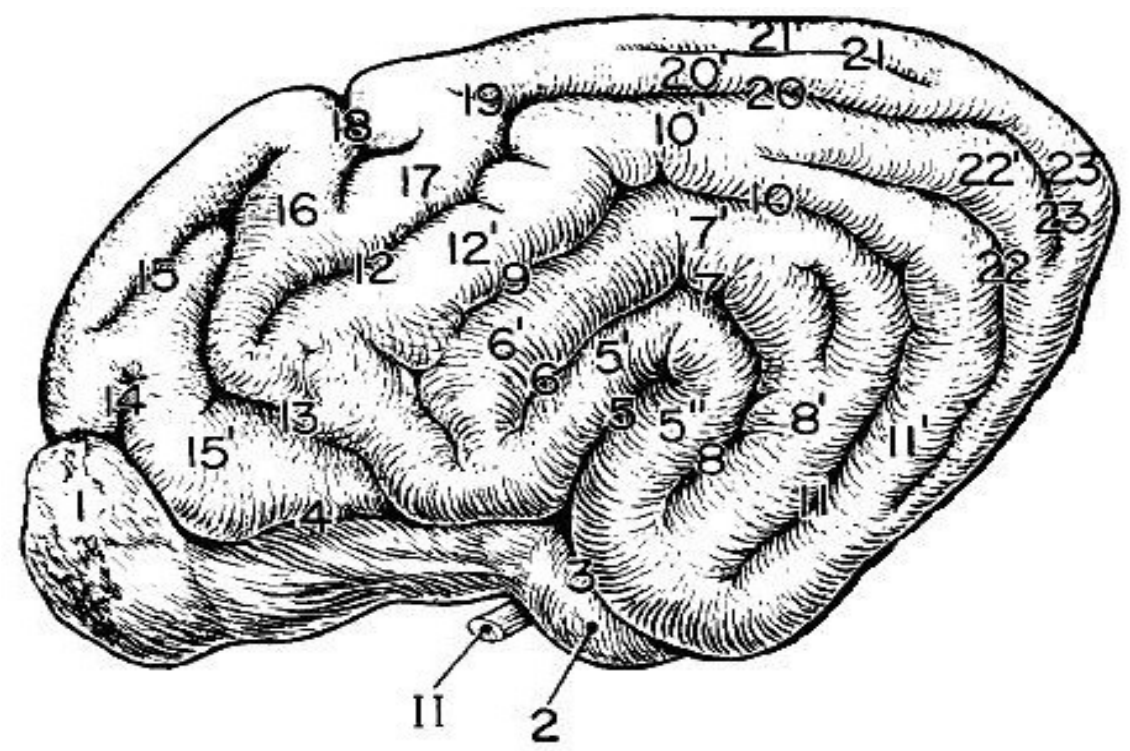

FIGURA 3 - Visão lateral do cérebro do hemisfério esquerdo de Cão (Miller et al 1964)- 1- Bulbo olfatório; 2- Área piriforme; 3- sulco rinal caudal; 4- Sulco rinal ventral; 5Sulco silviano; 5'- Giro silviano ventral; 5" Giro silviano caudal; 6- Sulco ectosilviano ventral; 6'- Giro ectosilviano ventral; 7- Sulco ectosilviano medial; 7'-Giro ectosilviano caudal; 8-Sulco ectosilviano caudal; 8'- Giro ectosilviano caudal; 9- Sulco suprasilviano ventral; 10- Sulco Suprasilviano medial; 10'-Giro suprasilviano medial; 11- Sulco Suprasilviano caudal;11'-Giro Suprasilviano caudal;12- Sulco Coronal;12'- Giro coronal;13- Sulco pré-silviano; 14- Sulco olfatório; 15- Sulco proreus; 15'- Giro proreus; 16- Giro sigmóide ventral; 17- Giro sigmóide caudal; 18- Sulco cruciato; 19- Sulco ansato; 20- Sulco lateral; 20'- Giro lateral; 21- Sulco entolateral; 21' Giro entolateral; 22- Sulco ectolateral; 22'- Giro ectolateral; 23- Sulco caudolateral; 23'- Giro caudolateral.

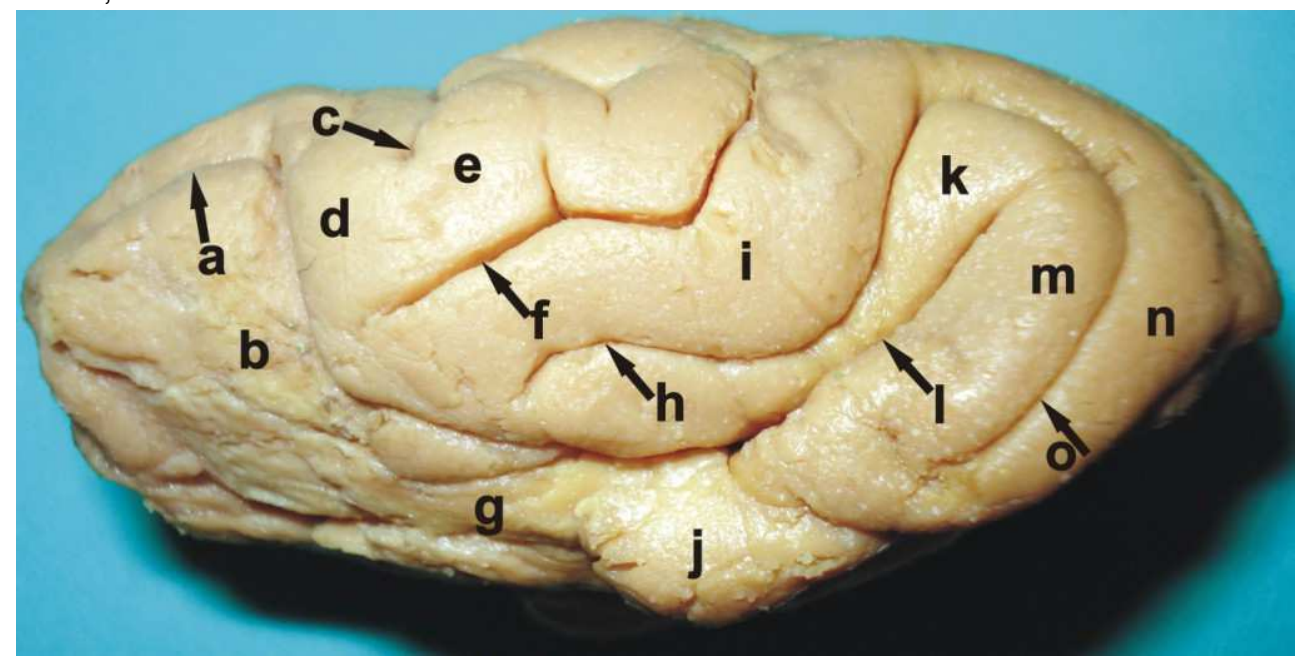

FIGURA 4 - Visão lateral do cérebro do hemisfério esquerdo de quati : a- Sulco Proreus, b- Giro Proreus, c- Sulco Cruzado, d- Giro Sigmóide Rostral, e- Giro Sigmóide Caudal, f- Sulco Suprasilviano, g- Tracto olfatório, h- Sulco Ectosilviano Rostral, i- Giro Ectosilviano Rostral, j- Área Piriforme, k- Giro Silviano Rostral, l- Sulco Silviano, m- Giro Silviano Caudal, n Giro Suprasilviano Caudal, o- Sulco Suprasilviano Caudal. Fonte: Tarley Santos Oliveira, Zenon Silva. 


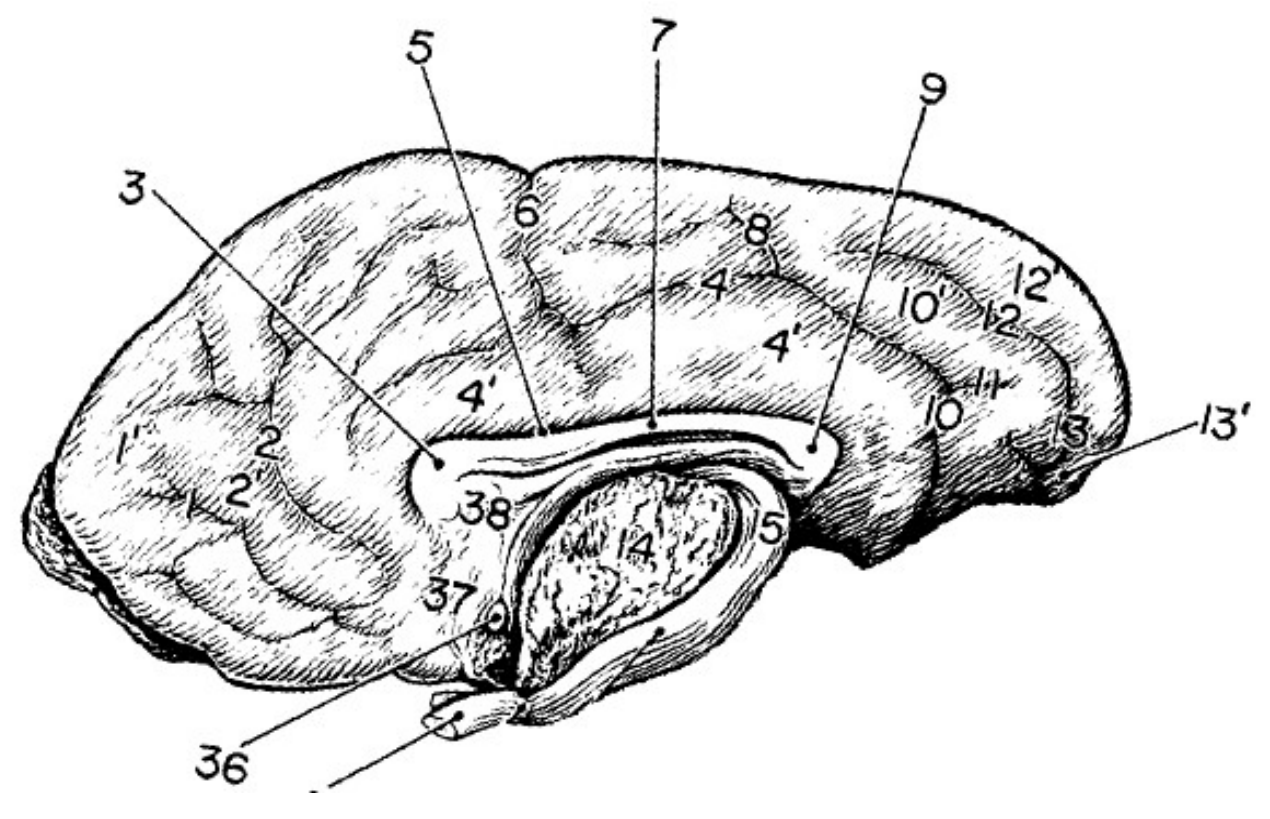

FIGURA 5 - Vista medial do hemisfério cerebral direito de Cão (Miller et al 1964) 1- Sulco ectolateral; 1'- Giro ectolateral; 2- Sulco genual; 2'- Giro genual; 3- Joelho do corpo caloso; 4- Sulco do cíngulo; 4'- Giro do cíngulo; 5- Sulco do corpo caloso; 6- Sulco cruzado; 7- Tronco do corpo caloso; 8- Sulco cruzado menor; 9- Esplênio do corpo caloso; 10- Sulco Esplenial; 10'- Giro esplenial; 11- Ramo horizontal posterior do sulco esplenial; 12- Sulco supraesplenial; 12'- Giro supraesplenial; 13- Sulco pós-esplenial; 13'- Giro pósesplenial; 37- Giro paraterminal; 38- Septo pelúcido.

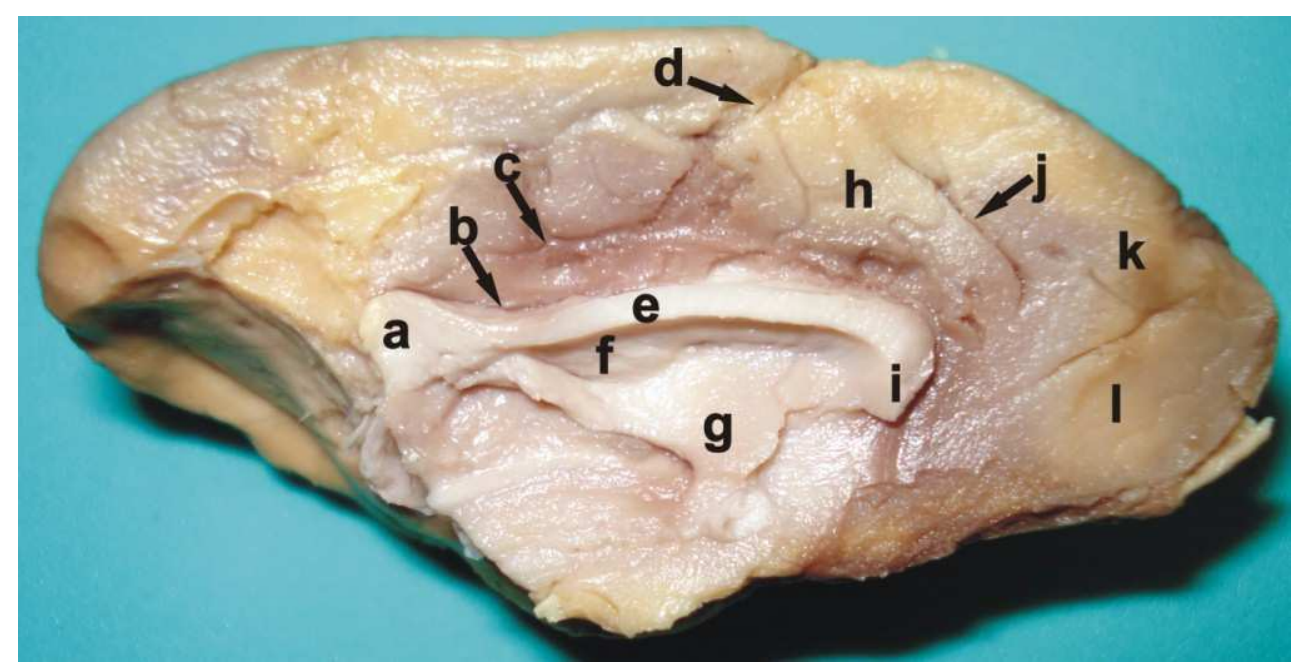

FIGURA 6 - Vista medial do hemisfério cerebral esquerdo de quati : a- Esplênio do Corpo Caloso, b- Sulco do Corpo caloso, c- Sulco do Cíngulo, d- Sulco Cruzado, e- Tronco do Corpo Caloso, f- Septo Pelúcido, g- Fórnix, h- Giro do Cíngulo, i- Joelho do Corpo Caloso, j- Sulco Genual, K- Giro Lateral, I- Giro Reto.

Fonte: Tarley Santos Oliveira, Zenon Silva. 


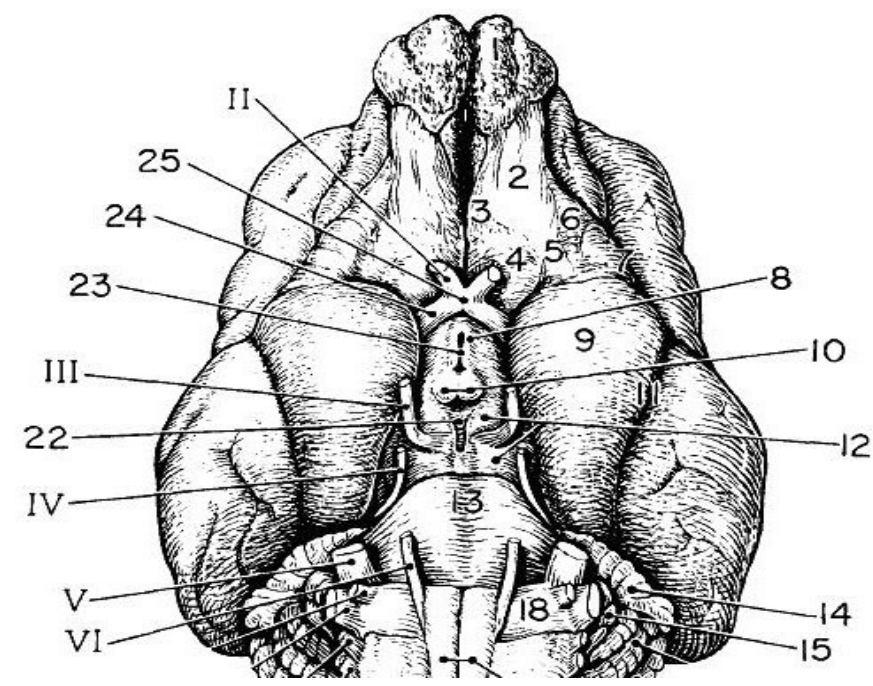

FIGURA 7 - Vista ventral do cérebro de Cão (Miller et al 1964) - 1- Bulbo olfatório; 2Tracto olfatório; 3- Estria olfatória medial; 4- Substância perfurada rostral; 5- Estria olfatória lateral; 6- Giro olfatório lateral; 7- Sulco rinal rostral; 8- Túber cinéreo; 9- Área piriforme; 11- Sulco rinal caudal.

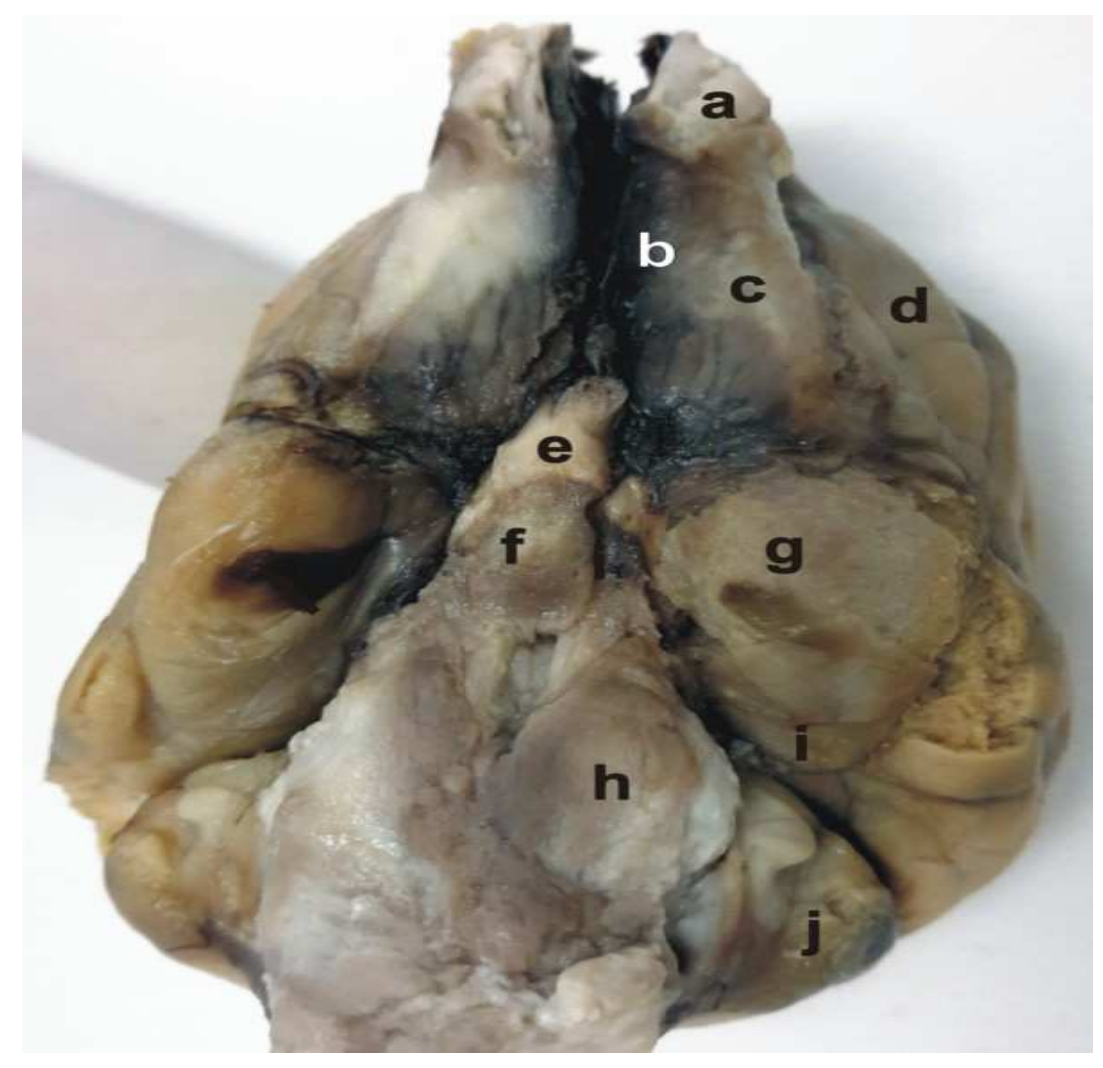

FIGURA 8 - Vista ventral do cérebro de quati: a- Bulbo olfatório, b- Estria olfatória, cTrato olfatório, d- Giro Proreus, e- Quiasma óptico, f- Hipófise, g- Área Piriforme, hPedúnculo Cerebral, i- Giro Parahipocampal, j- Cerebelo.

Fonte: Tarley Santos Oliveira, Zenon Silva. 


\section{DISCUSSÃO}

O telencéfalo de Quati é relativamente desenvolvido em relação ao tamanho do animal. É a parte mais desenvolvida do sistema neural, é globoso e quando visto de uma perspectiva dorsal é alongado à semelhança de um "grão de bico" (Cicer arietnum). É dividido em hemisférios direito e esquerdo através da Fissura Longitudinal em conformidade com as descrições de MILLER et al (1964) em Cão Doméstico.

Segundo MILLER et al (1964) o telencéfalo de Cão Doméstico está dividido em lobos Frontal, Parietal, Temporal e Occipital, mas em Quati, essa topografia é verificada, uma vez que a maioria dos sulcos e giros estendemse por todo o hemisfério. $O$ desenvolvimento da córtex levou ao aparecimento de numerosos sulcos e giros em cão MILLER et al (1964) e GETTY in SISSON e GROSSMAN, 2008), condição igualmente verificada em quati, no entanto, os sulcos são mais superficiais e os giros mal definidos e mais retilíneos, sugerindo uma córtex menos desenvolvida.

Sulcos da face dorsolateral - Conforme descrevem MILLER et al (1964), em cão, o sulco mais constante e bem definido é o Sulco Rinal. Com localização ventrolateral em cada hemisfério, que se estende ao longo de todo o hemisfério cerebral. Em quati verifica-se uma condição semelhante àquela descrita em Cão. Outros sulcos guardam similitude entre as citações de MILLER et al (1964) em cão e em quati, assim em ambas as espécies, o Sulco Rinal está dividido em Rostral e Caudal e a disposição Caudo-ventral do Sulco Rinal é semelhante nos dois grupos, além disso, a presença de um sulco pré-silviano está posta nas citações em cão e também é verificada em quati.

Embora o cão e o quati pertençam a grupos taxonômicos diferentes, muitas semelhanças podem ser identificadas. Assim, a localização e morfologia do Sulco Rinal e do Sulco Pré-Silviano são semelhantes, todavia, enquanto a extremidade rostral do sulco pré-silviano em cão se ramifique em ramo cranial e ramo caudal, em quati há apenas o ramo cranial. Em cão, segundo MILLER et al (1964), os ramos rostral e caudal do sulco présilviano formam o sulco Proreus, enquanto em quati o Sulco ProReus é constituído apenas pelo ramo rostral do Sulco Pré-Silviano. Em cão, a continuação rostral do sulco Proreus denomina-se sulco olfatório, mas este não está presente em quati.

Em cão e em quati no ponto em que o Sulco Rinal passa a ser denominado Sulco Rinal Caudal, nasce um sulco bem definido que corre no sentido dorso-caudal, é o Sulco Silviano. Em ambas as espécies o Sulco Silviano é curto, profundo e largo e por vezes denominado Fissura Silviana.

Em cão, de acordo com MILLER et al (1964), o Sulco Silviano é rodeado por três sulcos igualmente constantes e semicirculares, dispostos concentricamente. O primeiro, mais próximo ao sulco Silviano é o Sulco Ectosilviano, seguido pelo sulco Supra Silviano e depois o Sulco Lateral ou Ectomarginal. Os sulcos ectosilviano e suprasilviano são semicirculares, em forma de ferradura e podem ser subdivididos em três partes: Rostral, Médio E Caudal. O sulco lateral, por sua vez é longo, disposto paralelamente à Fissura Longitudinal. A parte rostral é denominada Sulco Coronal, enquanto a parte caudal é o Sulco Caudo-Lateral. Um Sulco Ectolateral pode estar presente entre o Sulco caudo-lateral e o Suprasilviano Caudal. Próximo à extremidade do Sulco Coronal está presente um curto e profundo sulco 
transversal denominado Sulco Cruzado. Além disso, pode haver um pequeno Sulco Pré-Cruzado e outro Pós-Cruzado (MILLER et al 1964; GETTY in SISSON e GROSSMAN, 2008).

Em quati verificam-se os sulcos ecto e supra silvianos dispostos similarmente àqueles descritos em cão, mas o sulco lateral está presente apenas próximo ao pólo occipital do hemisfério. Vários pequenos sulcos inominados são descritos em cão e estão igualmente presentes em quati, porém em menor número e mal definidos.

Giros da Face Dorsolateral - Para MILLER et al (1964), na face dorsolateral do hemisfério cerebral de Cão, são encontrados alguns giros bem definidos e outros mal definidos. A área localizada rostralmente ao Sulco PréFrontal é o Giro Proreus. Outros quatro grandes giros estão dispostos concentricamente em volta do Sulco Silviano, são o Giro Silviano, Ectosilviano, Suprasilviano e o Giro Lateral. Os dois primeiros giros, em forma de ferradura, podem ser divididos em Rostral Médio e Caudal.

O Giro Supra Silviano é mais aberto e a parte rostral denomina-se Giro Coronal. O Giro Lateral ou Giro Marginal ocupa uma faixa ao longo da Fissura Longitudinal. A parte rostral é cortada transversalmente pelo Sulco Cruzado e as partes que contornam o sulco cruzado, MILLER et al (1964), as denominam Giro Sigmóide.

A face dorsolateral do hemisfério cerebral de quati é cortada por numerosos sulcos os quais delimitam áreas denominadas giros ou circunvoluções, no entanto a superfície cerebral de quati é consideravelmente mais lisa do que a de Cão. O giro Proreus está localizado próximo à extremidade rostral da face dorsolateral em concordância com as citações de MILLER et al (1964) em Cão, todavia, assim como ocorre com os demais giros, em quati, são menos pronunciados do que em Cão. Os Giros Sigmóides Rostral e Caudal de quati, embora, bem definidos são mais retilíneos do que em Cão. Enquanto MILLER et al (1964), descrevem, em Cão, quatro giros concêntricos ao Sulco Silviano, em quati apenas três giros estão presentes, não há Giro Supra-Silviano em quati.

Sulcos e giros da face ventral - A face ventral do hemisfério cerebral de quati, apesar de um tanto irregular, não apresenta nenhum sulco ou giro bem marcado, sobressaindo a Área Piriforme, o Giro Parahipocampal e o Tracto Olfatório, mas em Cão, segundo MILLER et al (1964), as principais irregularidades da face ventral são representadas pelo Bulbo Olfatório, Área Piriforme, Estria Olfatória e Giro Olfatório sugerindo irregularidades mais pronunciadas em Cão.

Sulcos e Giros da face Medial - A face medial do hemisfério cerebral de quati é relativamente lisa, mostrando apenas o Sulco do Corpo Caloso e o Sulco do Cíngulo mais bem marcados. Na parte média do hemisfério o Sulco do Cíngulo curva-se, bruscamente, no sentido dorsal, avançando sobre a superfície dorsolateral do hemisfério, como Sulco Cruzado. Um pequeno sulco localizado rostralmente ao joelho do corpo caloso é descrito como Sulco Genual. O Corpo Caloso é bem definido e os sulcos do corpo caloso e do cíngulo delimitam o Giro do Cíngulo como principal giro desta face. O Giro Lateral, o Fórnix e o Septo Pelúcido também se fazem presentes.

Segundo MILLER et al (1964), a face medial do hemisfério cerebral de Cão exibe alguns sulcos e giros bem definidos, além do Corpo Caloso igualmente bem delimitado. O Sulco do Corpo Caloso é relativamente bem 
marcado e acompanha toda a extensão deste. O Joelho, Tronco e Esplênio do corpocaloso são bem delimitados, em conformidade com o que é verificado em quati. O Sulco do Cíngulo pode ser subdividido em Rostral, Médio e Caudal. Outros sulcos tais como Ectomarginal, Genual, o Esplenial, Supraesplenial e o Pós-Esplenial estão presentes, mas não são em quati, esses sulcos delimitam os giros: Genual Ectogenual e Pós-Esplenial. O Giro Parahipocampal representa a continuação caudal do giro do cíngulo, como em quati.

\section{REFERÊNCIAS}

COUTINHO, L.M. O conceito de bioma. Acta Botânica Brasileira , 2006. Disponível em:

http://ecologia.ib.usp.br/ecovegetal/leituras/Coutinho conceito bioma ACTA 2 0\%28 1\%29_T_02.pdf> acessado em 05 abr. 2016.

GETTY, R. Sisson \& Grossman: anatomia dos animais domésticos volume 1. 5 ed. Rio de Janeiro: Guanabara Koogan, 2008.

GREGORES, G.B; BRANCO, E; CARVALHO, A.F; SARMENTO, C.A.P; OLIVEIRA, P.C; FERREIRA, G.J; CABRAL, R; FIORETTO, E.T; MIGLINO, M.A; CORTOPASSI,

S.R.G. Topografia do cone medular do quati (Nasua nasua Linnaeus, 1766).

Biotemas, São Paulo, junho de 2010. Disponível em:

$<$ https://periodicos.ufsc.br/index.php/biotemas/article/view/2175-

7925.2010v23n2p173/17334>. Acessado em: 25 jun. 2016.

\section{INTERNATIONAL COMMITTEE ON VETERINARY GROSS} ANATOMICAL

NOMECLATURE. Nomina anatomica veterinaria. 4. ed. New York, 1994: (Togheter with nomina histologica, 2. ed., 1992 and nomina embriologica veterinaria, 1992).

MARINHO-FILHO, J. The Brazilian Cerrado bat fauna and its conservation.

Chiroptera Neotropical, Brasília-DF, jun. 1996. Disponível em:< http://www.chiropteraneotropical.net/index.php/cn/article/view/119/119>.

Acessado em: 02 jul. 2016.

MARINHO-FILHO, J.; RODRIGUES, F. H. G.; JUAREZ, K. M. The Cerrado

mammals: diversity, ecology and natural history. In: The Cerrados of Brazil: Ecology and Natural History of a Neotropical Savanna. OLIVEIRA, P. S.; MARQUIS, R. J. New York: Columbia University Press, 2002.

MILLER, CHRISTENSEN E EVANS. Anatomy of the Dog. New York: W.B.

Saunders Company. 1964. 
OLIVEIRA, P. S.; MARQUIS, R. J. The Cerrados of Brazil: Ecology and Natural History of a Neotropical Savanna. New York: Columbia University Press, 2002. 